\title{
Construindo a universidade que queremos
}

\author{
Building the university we want
}

Iolanda de OLIVEIRA ${ }^{1}$

\begin{abstract}
Resumo
Esta produção resulta da participação da autora no SemiEDU 2020: Educação Intercultural e Direitos Humanos em Tempo de Pandemia, subtema: Direitos Humanos e Educação das Relaçóes Étnico-Raciais. Incorporam-se também alguns aspectos apresentados na XIII Jornada Desigualdades Raciais na Educação Brasileira, promovida pelo Núcleo de Estudos e Pesquisas sobre Relações Raciais e Educação (NEPRE/UFMT), realizada em 2019. O propósito deste artigo consiste em evidenciar, a partir das referências consultadas, os enfrentamentos necessários para construir uma instituição pública que, corroendo a sua finalidade original, coloque as suas funções a serviço da promoção da população brasileira, em particular dos negros e de outros grupos socialmente deserdados. Percebe-se que há um processo em curso, perpassado pela necessidade de avançar em busca de novas conquistas.
\end{abstract}

Palavras-chave: Negros. Universidade. Igualdade. Antirracismo.

\begin{abstract}
This production results from the author's participation in SemiEDU 2020: Intercultural Education and Human Rights in a Time of Pandemic, sub-theme: Human Rights and Ethnic-Racial Relations Education. Some aspects presented in the XIII Jornada Desigualdades Raciais na Educação Brasileira, promoted by Núcleo de Estudos e Pesquisas sobre Relaçóes Raciais e Educação (NEPRE/UFMT), in 2019. The purpose of this article is to highlight, from the references consulted, the confrontations necessary to build a public institution that, undermining its original purpose, places its functions at the service of the promotion of the Brazilian population, in particular blacks and other socially disinherited groups. It is noticed that there is an ongoing process, permeated by the need to move forward in search of new achievements.
\end{abstract}

Keywords: Blacks. University. Equality. Anti-Racism.

1 Doutora em Psicologia Escolar e do Desenvolvimento Humano - USP. Professora do Programa de PósGraduação em Educação - UFF. Professora do Programa de Educação sobre Negros e Indígenas na Sociedade Brasileira- Penesbi/UFF. Lattes: http://lattes.cnpq.br/0320659276314345. Orcid: https:// orcid.org/0000-0002-6314-6651.E-mail: iolanda.eustaquio@gmail.com 


\section{A Universidade brasileira: origem e movimento contemporâneo}

Prolongando a investigação intitulada Negritude e Universidade (OLIVEIRA, 2015), aponta-se aqui a necessidade de analisar o presente, não como fetiche, ou seja, algo mágico que existe por si mesmo de forma independente, mas sim como resultante de uma construção histórica, ainda que o percurso desta construção seja permeado de avanços e rupturas, fenômeno que é evidenciado ao longo da história da humanidade.

Considerando a importância de analisar o presente como história, recorrese a alguns autores, destacando-se José de Souza Martins, que, na abertura da 35a Reunião da Anped/ 2012, afirmou: "é preciso analisar o presente como história”. Igualmente, destaca-se Alfredo Veiga-Neto (2012), que apresenta artigo intitulado "É preciso ir aos poróes", no qual recorre à metáfora de Bachelard sobre "a casa e as nossas posiçóes e atitudes diante do mundo"(VEIGA-NETO, 2012, p. 269). Fazendo referência à casa, o autor aponta o porão como o lugar onde estão as raízes e os fundamentos que lhe dão sustentação, a partir da racionalidade. O sótão é considerado o lugar onde a sublimação e a imaginação acontecem, avançando para além da parte intermediária, o cotidiano, onde as experiências imediatas ocorrem, isto é, onde a vida concreta acontece, por meio das práticas sociais cotidianas, rotineiras.

Manter-se no cotidiano pode ser confortável, mas significa omitir as raízes dos problemas, a reflexão e a razão que nos levam para além das experiências imediatas. Ir aos poróes permite alcançar uma posição mais elevada, caracterizada pela imaginação criadora e pelo avanço em busca da inovação e, certamente, da superação da mesmice cotidiana, com vistas ao progresso e à transformação pretendidas, avançando para o sótão, para além do estabelecido, desconstruindo equívocos cotidianos e, entre estes, os preconceitos e as segregaçóes que, naturalizadas, afetam aos grupos socialmente deserdados.

$\mathrm{O}$ recurso à história dos fenômenos contemporâneos, segundo Veiga-Neto (2012), é a maneira mais segura para a devida compreensão do presente e, sem dúvida, para permitir alçar o sótão como lugar da transformação. Abandonar a história do presente significa naturalizá-la, tomando-a como verdade desprovida de ocorrências precedentes, isto é, sem raízes.

Buscando evidenciar a coexistência da autonomia universitária com as referências histórico-espaciais, Oliven (2005) faz um confronto entre a origem da universidade nos Estados Unidos e no Brasil. Os colleges nos Estados Unidos surgem no século XVII, liderados por protestantes, perseguidos por suas práticas religiosas na Inglaterra. Embora mantenham aspectos da tradição universitária inglesa, tiveram grande independência em relação à metrópole, 
sendo não conformistas em sua maioria, principalmente por motivos religiosos: vários colleges foram instituídos sem a autorização da Inglaterra, marcados pelo comprometimento com a formação de pastores e líderes religiosos por meio da leitura e discussão da Bíblia.

Parece que a postura dessas instituiçóes diante da Bíblia como conhecimento revelado e, portanto, inquestionável, o caráter religioso da formação com base neste documento, compromete a afirmativa de Nogueira (2004), o qual observa que historicamente a universidade teve como função "produzir e transmitir conhecimento, acumular e disseminar pensamento crítico". A universidade norte-americana, pelo menos nesse momento histórico, rompe com a funçáo de produzir conhecimento, porque nela predomina um conhecimento revelado, provavelmente lido e discutido, desprovido de uma postura crítica, mas caracterizado pela submissão ao revelado, que, para os adeptos da respectiva religião, é inquestionável, dogmático, o que se opõe à produção de conhecimentos científicos como função primeira da universidade.

Ao contrário do que ocorreu nos Estados Unidos, a universidade brasileira tem origem no Império, emerge como política colonizadora, cujas primeiras instituições são criadas no início do século XIX, no momento em que a família real migra para o Brasil em decorrência dos ataques napoleônicos. Junto a outras instituiçóes culturais, são criados os cursos de Belas Artes, o Museu Nacional e o Jardim Botânico. As primeiras faculdades brasileiras - de Medicina, Direito e Politécnica eram orientadas pela profissionalização, baseadas em cátedras vitalícias.

As faculdades de Direito, criadas respectivamente em São Paulo e em Olinda, datam do século XIX, tendo sede em Ouro Preto uma Escola de Minas, por motivo de ser essa uma região de extração de ouro. As faculdades de Medicina, criadas na mesma época, foram localizadas na Bahia e no Rio de Janeiro. A primeira universidade brasileira, a Universidade do Brasil, no Rio de Janeiro, atualmente Universidade Federal do Rio de Janeiro (UFRJ), surge somente em 1920, em pleno período da Primeira República, quando teve origem o ideal de branqueamento.

As características de tais instituiçóes na época as mantiveram desvinculadas dos interesses e necessidades da maior parte da população brasileira, principalmente da população negra, a despeito das conquistas alcançadas pelos movimentos de resistência já existentes, os quais são evidenciados desde os primórdios da colonizaçáo.

Foi criado em 1931, pelo primeiro ministro da Educação do país, o Estatuto das Universidades Brasileiras, que teve sua vigência até 1961, quando se tem a primeira Lei de Diretrizes e Bases da Educação Nacional. O estatuto estabelecia que para criar uma universidade seriam necessárias pelo menos as seguintes faculdades: Medicina, Engenharia, Direito, Educação, Ciências e Letras.

A criação da Universidade de São Paulo (USP), em 1934, tem uma proposta inovadora em relação aos objetivos da universidade, por se destacar como centro 
de pesquisa em várias áreas de conhecimento. $\mathrm{Na}$ sua organização, que sem dúvida teria influência direta nos currículos, a ideia era a de fazer da Faculdade de Filosofia, Ciências e Letras um eixo integrador do ensino básico e da pesquisa, o que não ocorreu por motivo da resistência das faculdades tradicionais.

É possível que a ruptura provocada no modelo de universidade brasileira, pela USP, tenha ocasionado a abertura para a realização das pesquisas sobre o negro pelos sociólogos Florestan Fernandes, Oracy Nogueira, Otávio Ianni, Fernando Henrique Cardoso, entre outros, destacando-se, no período, a socióloga e psicanalista negra Virgínia Bicudo.

Paralelamente ao que foi descrito anteriormente, o contexto das discussóes que precederam a Primeira República e a Abolição, teve a questão racial como um dos principais fatores, prolongando-se por todo o período citado. É neste momento que, distanciando-se muito mais do seu papel originário da Idade Média, a universidade se presta para afirmar e disseminar as equivocadas ideias européias sobre a diversidade racial humana.

Oficializada a náo escravidáo, o governo republicano, em lugar de promover políticas públicas para garantir à população negra o acesso aos direitos humanos, com o respaldo dos discursos oriundos principalmente das faculdades de Medicina e de Direito, toma medidas políticas para o seu desaparecimento, sem, entretanto, documentar explicitamente a segregação que as medidas governamentais provocaram.

Em sua evolução, com a reforma universitária de 1968, Lei 5.540, não parece que a universidade trouxe respostas às reivindicações e aspiraçóes da população negra sobre educação, representada pelo movimento negro ao longo dos anos, sobretudo por motivo da referida legislação ser datada do período de ditadura militar. Deve-se, entretanto, atentar para a qualificação do Ensino Superior na época, destacando-se a instituição da pós-graduação, que aprimorou a formação docente e a institucionalização da pesquisa indissociável do ensino e da extensão. Estas medidas contribuíram fortemente para a construção da universidade pública brasileira.

Concorda-se com Luiz Antônio Cunha (1989) sobre a insuficiência do caráter indissociável das três funçóes atribuídas à universidade e sobre a necessidade de que se estabeleça uma hierarquia colocando a pesquisa em primeiro plano, o que contribuirá para o aprimoramento qualitativo do ensino e da extensão, como funçôes do Ensino Superior.

A despeito das discussões e pesquisas, mencionadas anteriormente, realizadas em São Paulo, as quais tiveram o patrocínio da UNESCO, as políticas públicas para promoção da população negra somente conseguem espaço a partir da década de 1990, com ganhos extremamente expressivos na primeira década do século XXI, com dois eixos em educação: um primeiro, a nível nacional, com a 
aprovação da Lei 10.639/03; e um segundo eixo, a princípio por iniciativa de várias universidades públicas, que determinaram cotas para ingresso de negros no Ensino Superior, ainda que em sua maioria seja evidenciada a subsunção da raça em relação à classe.

Posteriormente, a Lei 12.711/2012, ratifica a nível nacional as cotas no ensino superior federal, mantendo o equívoco anteriormente apontado, isto é, a vinculação do direito às açóes afirmativas, à frequência integral do Ensino Médio em instituiçóes públicas, representando um retrocesso para algumas universidades que anteriormente não estabeleciam tal exigência, reconhecendo a autonomia entre o binômio raça/classe.

Ambos os eixos, sendo políticas particularmente destinadas à parcela negra da população, pelo menos enquanto aspecto legal, mantêm o seu caráter particular, como políticas de açóes afirmativas para a promoção de pretos e pardos.

A universidade brasileira é, portanto, atualmente acionada pela legislação vigente a cumprir um duplo papel na promoção da população negra em educação: pela Lei 10.639/03, que, determinando a inclusão dos estudos sobre o negro nos currículos de todos os cursos na Educação Básica, tem necessariamente, implicações na formação de professores pela universidade. O segundo papel, determinado inicialmente pela iniciativa de algumas universidades públicas, passa em 2012 a ser uma determinação para as instituiçóes federais de educação, tendo também, de forma indireta, um caráter universal, porque promove a convivência da diversidade racial brasileira, o que tem, em potencial, a possibilidade de alterar o comportamento de grupos privilegiados presentes nas instituiçóes.

As alteraçóes curriculares determinadas em 2003, têm implicações não somente na formaçáo de professores, mas também nos demais cursos por determinação da Resolução no 01/2004:
Art. $1^{\circ}$ Parágrafo $1^{\circ}$ As Instituiçóes de Ensino Superior incluirão nos conteúdos de disciplinas e atividades curriculares dos cursos que ministram, a Educação das Relaçóes Étnico-Raciais, bem como o tratamento de questóes e temáticas que dizem respeito aos afrodescendentes, nos termos explicitados no Parecer CNE/CP 3/2004.

O segundo eixo, sendo uma política de ação afirmativa que tem como ponto de partida o aspecto quantitativo, tem também suas implicaçóes qualitativas por motivo de provocar nos cursos a convivência inter-racial com mais intensidade, pela presença mais expressiva de negros, embora ainda muito distante de corresponder ao percentual de negros na populaçáo, atualmente 55\% (PNAD, 2017). Particularizando a questão curricular, constata-se que os 
dois eixos se cruzam em todos os contextos porque ambos alteram a convivência no interior da universidade.

A mobilização sobre o tema negro e educação foi provocada no interior das instituições de educação, de forma mais intensa, somente a partir da primeira década do século anteriormente mencionado, por motivo da legislação datada de 2003. Por outro lado, no contexto da prática, as alteraçóes curriculares se deram minimamente, em situaçóes pontuais, muito distantes de uma ação político/ pedagógica com a ousadia necessária para alterar a realidade.

Torna-se importante acrescentar que, no final do século XX, foram promovidas políticas públicas para a promoção da igualdade racial, principalmente por meio da criação do Grupo de Trabalho Interministerial (GTI), responsável pela discussão, elaboração e implementação de projetos, visando à valorização dos negros brasileiros e a elevaçáo dos seus padróes de vida. A complexidade da questão exigiu a subdivisão do GTI em 16 subgrupos: 1 - Informação - quesito cor, 2 --Trabalho e Emprego, 3 - Comunicação, 4 - Educação, 5 - Relações Internacionais, 6 - Terra (Remanescentes de Quilombos), 7 - Política de Ação Afirmativa, 8 - Mulher Negra, 9-Racismo e Violência, 10 - Saúde, 11 - Religiáo, 12 - Cultura Negra, 13 - Esportes, 14 - Legislação, 15 - Estudos e Pesquisas e 16 - Assuntos Estratégicos.

Composto por representantes do Movimento Negro e do Estado, este grupo de trabalho emerge das propostas do movimento mencionado, que, ao longo da nossa história, reivindica tais políticas, sendo enumeradas algumas conquistas anteriores, descritas por investigadores do tema, tais como Hanchard (2001), Pereira (2007), entre outros.

Sem descartar os méritos do GTI, entre os quais, a proposição da política de açóes afirmativas para negros em diferentes setores, destacando-se o ingresso e permanência na universidade, percebe-se na composição do grupo, a ausência de representantes da universidade, cuja contribuição teórica disponível naquele período já era extremamente relevante, com significativo potencial para dar sustentação às propostas e possíveis outras. Aponto a ausência da universidade no GTI como um equívoco na composição do grupo, a despeito de o Presidente da República da época ser oriundo dos quadros docentes da Escola de Sociologia e Política de São Paulo, instituição esta cuja produção científica sobre o negro na segunda metade do século XX tornou-se clássica como parte do acervo científico nacional, projetando-se internacionalmente.

Apesar das conquistas apontadas, que têm provocado a mudança do perfil dos estudantes e, portanto, a cor do quadro discente universitário, emerge a necessidade de analisar criticamente os avanços em confronto com a situaçáo ideal, em uma sociedade legalmente democrática, comprometida com o acesso de todos aos direitos humanos e signatária da declaração decorrente da III 
Conferência Mundial contra o Racismo, Discriminação Racial, Xenofobia e Intolerância Correlatas realizada na África do Sul em 2001.

No início do século XXI, as propostas de ação afirmativa do GTI se efetivam parcialmente no âmbito da legislação, com destaque na educação, o que representa expressivo avanço. Tais progressos deveriam alterar universalmente os currículos de toda a educação neste nível, da Educação Infantil ao Ensino Médio, estendendo-se, conforme a legislação mencionada, a todo o Ensino Superior, o que exige a competência e o compromisso político de todos os profissionais do magistério, em todos os níveis, para garantir a efetiva realização das conquistas legais em todos os espaços da prática educativa institucionalizada.

Entende-se como competência o domínio de conhecimentos sobre a questão negra nas diferentes áreas de conhecimento, atrelado aos aspectos didático-curriculares que permitem ao educador realizar a mediação entre os conhecimentos racialmente relevantes e o nível de desenvolvimento intelectual dos destinatários do trabalho docente. Acrescenta-se aos educadores a necessidade de atentar para o aspecto emocional de todos os estudantes, porque não se trata de ministrar conhecimentos neutros em relação ao psiquismo dos discentes, independente da identidade racial de negros e náo negros. Não raro, percebemse reaçóes comportamentais diversas de parte dos alunos ao terem o domínio de conhecimentos que comprovam cientificamente os equívocos do racismo e a maneira pela qual a sociedade produz as desigualdades raciais.

Se, por um lado, os efeitos da naturalização do racismo e das desigualdades raciais são extremamente perversos, condicionando a vida material e emocional de sujeitos, a tomada de consciência da inconsistência daqueles dois aspectos atinge igualmente estas duas áreas da dimensão humana com uma significativa diferença, porque o segundo possibilita formar sujeitos com potencial transformador, condição necessária, ainda que não suficiente, para desconstruir a racializaçáo do mundo.

Os comportamentos mencionados tanto em relação à naturalização quanto em relação à tomada de consciência do racismo e das desigualdades raciais não ocorrem somente na Educação Básica, mas em todos os níveis e modalidades do ensino e mesmo nas relaçóes cotidianas, independente do nível de desenvolvimento e da faixa etária dos educandos/educadores.

No momento, pode-se afirmar que o ensino superior público federal está assentado em bases legais cujo cumprimento provocaria grandes mudanças principalmente no perfil racial discente; não se tem dúvida de que, a despeito dos equívocos evidenciados na legislação, as práticas no interior das universidades têm contribuído para que a instituição tenha o perfil que corresponda às características fenotípicas da população brasileira, o que é pertinente às exigências estabelecidas pelo Estado, como condição necessária para que as mesmas se efetivem. Mas tais 
açôes não suficientes para garantir que a formação ministrada no seu interior tenha o comprometimento efetivo com a desconstruçáo do racismo epistemológico que caracteriza o Ensino Superior brasileiro ao longo de sua história.

Os cursos de pós-graduação, vinculados diretamente à administração federal, têm, a partir de 2016, a Portaria Normativa no13, do Ministério de Educação, que dá sustentação legal às políticas de ações afirmativas nos cursos de mestrado e doutorado e às comissóes para o acompanhamento e avaliação das políticas estabelecidas. O documento legal menciona negros (pretos e pardos), indígenas e pessoas com deficiência como destinatários das políticas a serem estabelecidas. Entretanto, tendo como fundamento a autonomia universitária, várias instituições incluíram também candidatos autodeclarados pertencentes ao grupo LGBTQI+, entre possíveis outros.

Por outro lado, verifica-se nas políticas destinadas à Educação Básica, que deveriam alterar os currículos, a predominância do aspecto qualitativo, por serem destinadas a alterar a dinâmica da escola, que é o espaço da prática. As alteraçóes legais que deveriam tornar-se universais, atingindo a todas as instituições escolares públicas e privadas desde a Educação Infantil até o Ensino Médio, tornaram-se excepcionais, a despeito de a legislação ser datada do início do século.

A situação mencionada comprova que entre a produção do texto legal e sua efetivação no espaço da prática, há uma série de fatores que condicionam a relação de unidade entre a legislação e a dinâmica didático-curricular. Deve-se atentar para o fato de que, sobretudo, os seres humanos adentram no ambiente escolar não como tábulas rasas nas quais a legislação será inscrita, mas com uma determinada formação ao longo da vida, um acúmulo de experiências e valores que interferem na sua atividade profissional. Acrescenta-se a omissão do poder constituído em relação à necessidade de garantir a todos os profissionais do magistério a formaçáo continuada, de preferência em serviço e/ou o necessário apoio institucional quando esta formação se dá em outra instituição.

Náo se tem dúvida de que o avanço da ciência e da tecnologia, a não estabilidade do ambiente humano e do mundo material, exigem da parte de todos os profissionais uma formação continuada que lhes possibilitem manter-se atualizados em sua área de atuação, tendo em relação ao conhecimento pertinente, no mínimo um comportamento crítico. Entretanto, preferencialmente, o profissional deverá também tornar-se um pesquisador, como participante de investigaçóes que disponibilizem para a humanidade conhecimentos que expliquem os problemas sociais mais emergentes. Sobre esta possibilidade, têm-se a Lei 11.738/2008, que institui o piso salarial profissional nacional para os profissionais do magistério público da Educação Básica, a qual no artigo segundo, parágrafo quarto, determina que: 
Na composição da jornada de trabalho, observar-se-á o limite máximo de dois terços da carga horária para o desempenho das atividades de interação com os educandos.

O texto legal respalda, portanto, a realização da formação continuada em serviço, que poderá ser uma alternativa para garantir a atualização permanente dos professores. Entretanto, há fortes evidências do não cumprimento da liberação determinada, ou do seu cumprimento parcial, não atingindo a todo o quadro docente.

Contempladas com a exclusividade no aspecto qualitativo na Educação Básica, exigindo alteraçóes didático-curriculares para os cursos de graduação e de pós-graduação, as determinaçóes legais restringem-se ao aspecto quantitativo, oportunizando uma formação desvinculada dos interesses e necessidades da populaçáo brasileira que ingressa em uma universidade. Apesar de incluir entre as conquistas recentes a criação dos núcleos de estudos e pesquisa sobre o negro, em alguns casos negros e indígenas, ainda permanece nos currículos das instituições de ensino superior a predominância de conhecimentos eurocentrados, desvinculados dos interesses nacionais, o que consiste em um racismo epistêmico que compromete a formação dos estudantes e, no caso da formação para o magistério, torna-se impedimento para que os currículos da educação básica sejam alterados.

Tratando-se da universidade, além da inclusão quantitativa para eliminar as desigualdades raciais no quadro discente e das alteraçóes curriculares, ambas providas de sustentação pedagógico/legal nos cursos de graduação, acrescentamse os enfretamentos necessários para eliminar a subsunção da raça em relação à classe social. Da suposta centralidade da condição socioeconômica em relaçáo aos demais determinantes da situaçáo de inferioridade dos grupos destinados às açôes reparadoras, emergem novas exclusôes dos grupos deserdados que não cursaram integralmente o Ensino Médio em instituiçôes públicas. Este aspecto da legislaçáo representa um retrocesso diante de alguns projetos de universidades, que, utilizando da sua autonomia, precederam a legislação, não condicionando o direito às ações afirmativas ao tipo de instituiçáo frequentada no ensino médio.

As determinaçóes legais sobre a questâo negra, datadas de 2003 e 2012, precedem a Portaria Normativano ${ }^{\circ}$ 13/2016 do MEC, que tem o propósito de induzir açóes afirmativas na Pós-Graduaçáo, o que, na época, de parte de algumas instituiçôes, por antecipação, constituía realidade.

Para a realização de tais tarefas, é preciso que seja estabelecida uma estreita relação entre o Movimento Negro e a Universidade, as quais em diálogo, respeitando suas diferentes funções, deverão realizar a atividade constituída, de um lado pelo Movimento negro, que deverá ao mesmo tempo propor ao Estado o estabelecimento de políticas públicas para combater o racismo e às desigualdade e por outro apontar os problemas que afetam a população negra, os quais estâo 
a exigir da universidade o exercício da sua função investigadora para esclarecêlos. De posse dos resultados das pesquisas que esclarecem os questionamentos sobre problemas sociais que colocam o negro em situação de inferioridade, o Movimento Negro, ao apropriar-se dos mesmos, deverá dar sustentação às suas reivindicaçóes, em busca da solução de problemas raciais ainda pendentes.

\section{Movimentos Sociais Negros e Universidade - funções e relações}

Sendo estratégias políticas institucionalizadas ou por meio de açôes individuais, as lutas antirracistas empreendem atividades concretas caracterizadas por reivindicaçóes para desconstruir o racismo e reparar os danos provocados pelas açóes excludentes no âmbito da sociedade. Ainda que com características diferenciadas, ao longo da história do negro no Brasil, as lutas antirracistas foram empreendidas, mesmo durante os séculos que precederam a abolição, por meio de denúncias, de reivindicaçóes e de práticas de combate ao racismo, com relevantes conquistas, destacando-se a educação.

O movimento social negro tem o mérito, ao longo de sua história, de apontar os problemas sociais que afetam à população preta e parda, o que contribui para dar significado social ao trabalho universitário, principalmente às atividades de pesquisa.

Pelos conhecimentos disseminados sobre as funçóes da universidade, percebe-se que esta instituição sempre esteve vinculada à sociedade em que se insere, evidenciando-se, não raro, o atendimento a interesses de determinados grupos, em detrimento de outros. Para construir a universidade que queremos, é preciso não somente recorrer à sua história, mas exige-se também que haja a determinação coletiva do perfil institucional que se pretende construir, o que, de alguma forma, vem sendo apontado parcialmente pelo movimento negro, como ator das conquistas do final do século XX e início do século XXI.

Considerando-se que a igualdade é um princípio com o qual o estado brasileiro compromete-se por meio da adesão a documentos nacionais e internacionais e sabendo-se que para tornar realidade tal princípio, deve-se migrar da igualdade formalmente assumida para a igualdade substantiva, a partir de dados evidenciados no interior da sociedade, compete à universidade realizar investigaçóes tendo a população majoritária como destinatária desta produção. Isto significa que, ao mesmo tempo em que os resultados das pesquisas devem ser incorporados ao ensino, deve-se não apenas ter os problemas enfrentados pela população majoritária como temas de investigação, mas dar aos saberes produzidos o caráter de coisa pública, disseminando-os junto a toda a população.

Sendo a linguagem acadêmica inacessível à grande maioria da população, em um país cuja média de anos de escolaridade somente na atualidade se aproxima 
dos nove anos, torna-se necessária a mediação entre os saberes e tecnologias produzidos pelas pesquisas e a população majoritária, que náo é iniciada nesta linguagem. A quem compete tal mediação?

Atualmente, conforme dados do INEP, são as universidades públicas que mais contribuem para a produção de conhecimentos, a despeito das tentativas de privatização de parte dos governos, sendo, portanto, nestas instituiçóes que os movimentos sociais organizados ou não deverão buscar, preferencialmente, sustentação convincente para a sua atuação.

Compete aos intelectuais genuínos (SANTOS, 1998), assumindo a sua independência, responder em suas pesquisas às demandas que se expressam através dos movimentos sociais. Devem ter o propósito de produzir uma consciência coletiva, por meio de investigaçóes pautadas pelo necessário rigor científico, comprometidas com elevado grau de confiabilidade, para dar sustentaçáo às reivindicaçóes de projetos nacionais alternativos em busca da igualdade substantiva. A partir da produção gradativa de uma consciência coletiva, desestabiliza-se a idéia de que o acesso aos direitos humanos são conquistas pessoais, e sim direitos sociais.

Segundo Milton Santos(1998), na atividade intelectual, o intelectual genuíno é aquele que, renunciando a um comportamento cômodo e conformista, busca de maneira incansável a verdade, não para deleite intelectual, mas abandonando a postura de mera testemunha da história, assume a busca intelectual de melhores caminhos para a sociedade, por meio do saber, tendo como contrapartida a renúncia à busca do poder, busca esta que corrói as funçóes acadêmicas de pesquisar e de disseminar para toda a sociedade os conhecimentos oriundos de uma prática intelectual genuína. A busca da autenticidade na produção acadêmica não é confortável, porque exige o inconformismo diante de práticas acadêmicas desvinculadas do comprometimento com a promoção da população majoritária, ou seja, para com os socialmente rechaçados.

Observa-se que, na prática de suas atividades, os profissionais do Ensino Superior enfrentam problemas que comprometem a qualidade da sua produção, diante de exigências quantitativas incompatíveis com produçóes inovadoras e socialmente relevantes. Reconhece-se que, a despeito da situação desfavorável, há um significativo número de produções que são extremamente relevantes para explicar problemas sociais e oferecer ao movimento negro contribuiçóes para fortalecer as suas reivindicaçóes. Para isto, é preciso que os conhecimentos colocados à disposição dos movimentos sociais pela universidade se constituam a partir de uma rigorosa análise da realidade com fidelidade, desprovida de interesses particulares, sendo este um forte desafio institucional universitário.

Segundo Adauto Novaes(2006), os autores dos textos do livro $O$ silêncio dos intelectuais, não definem e nem discutem a intervenção direta dos intelectuais nas práticas políticas, tendo nestas uma participação distante. Neste sentido, os autores 
negam ou pelo menos omitem a questão da participação dos intelectuais nos projetos de intervenção na realidade e mesmo as pesquisas cuja produçáo de saberes se dá a partir de projetos de açóes transformadoras, o que exige, no caso das pesquisas sobre as populações majoritárias, rigorosas reflexóes, cuja discussão não cabe no espaço deste artigo e, portanto, fica adiada para outra produção. Neste sentido, o autor não admite a possibilidade de realizar de modo concomitante projetos de transformação e de pesquisa, isto é, interferir na realidade e analisá-la com rigor. Em conformidade com a posiçáo do mesmo, pode-se admitir que os dois atores sociais atuem de forma diferenciada: de um lado, os movimentos sociais, apontando problemas da sociedade; e, de outro, a universidade incorporando as suas demandas, buscando compreender e explicar a realidade.

Busca-se, neste texto, caracterizar o intelectual como portador de autonomia racional do pensamento, que vai conferir a este sujeito autoridade para constatar, compreender, analisar e criticar a realidade. Este é o perfil do intelectual que interessa aos movimentos sociais em geral e, em particular, ao movimento negro, o qual certamente buscará no âmbito da sociedade os temas a serem privilegiados em suas pesquisas. Mas a quem compete disseminar tais saberes? Ainda que privilegie a atividade de pesquisa, de acordo com as funçóes da universidade, o intelectual poderá também disseminar os conhecimentos para a sociedade em geral, por meio das atividades de extensão. Entretanto, supôe-se que esta função está atrelada também e principalmente às atividades a serem realizadas pelos movimentos sociais.

Sobre a produção acadêmica que tem como tema a população negra, dados coletados nos bancos dos órgãos oficiais comprovam o seu crescimento nos últimos anos, com predominância na área da educação.

Sobre o movimento negro e a academia, Munanga(1997) afirma a existência, já no período de publicação da obra, a reciprocidade entre esses grupos, apontando o movimento negro buscando sustentação e esclarecimentos para as suas idéias e dúvidas sobre suas açôes políticas de mobilização e conscientização. Ao mesmo tempo, a academia revendo sua postura epistemológica e suas concepçóes em face às críticas do movimento negro sobre a sua produção, apontando o respectivo movimento como usuário direto das pesquisas acadêmicas.

Sobre a relação entre a academia e a militância, mesmo sendo extremamente positiva, segundo o mesmo autor, a primeira provocou na militância negra, não raro conformação universitária em nível de graduação e pós-graduação e organizada politicamente, o distanciamento das suas bases populares, nas quais deveria investir, fazendo a mediação entre o conhecimento formal e a populaçáo em geral, dando à produção universitária a forma de coisa pública.

Sendo a produção acadêmica em sua linguagem formal inacessível à população majoritária negra, cujo nível de escolaridade média não alcança o ensino 
fundamental completo, e sabendo-se que a cultura deve ser democratizada, tornase necessário que seja feita a mediação entre os saberes acadêmicos e as massas negras e não negras. Igualmente, os saberes produzidos sobre outros grupos que compóem a diversidade humana deserdada dos bens materiais e não materiais que garantem o exercício da cidadania deveráo ser acessados e por todos.

Referindo-se, ainda, ao relacionamento militância/academia, Munanga(1997) afirma também que as trocas nem sempre acontecem de forma harmoniosa, referindo-se a conflitos que fazem parte das relaçóes entre os grupos, contribuindo para o maior conhecimento crítico de ambos sobre o mundo afro-brasileiro. Em sua produção datada de 2019, referindo-se ao mesmo relacionamento, Munanga destaca as relaçóes estabelecidas entre os militantes negros que, em decorrência das políticas de açóes afirmativas, provocaram a significativa ampliação da sua presença nas instituiçóes universitárias, evidenciando conflitos entre universitários negros e antropólogos que atuam na qualidade de professores.

No momento, provocada pelas açóes afirmativas como conquistas dos movimentos sociais, a presença de grupos estigmatizados aumenta, acentuando a necessidade de que a universidade faça com urgência uma revisão da sua postura epistemológica. Entende-se também que a vinculaçáo dos movimentos sociais às suas bases deverá ser permanente, movimentos estes que, segundo o mesmo autor, têm sido os usuários diretos das pesquisas acadêmicas e não o poder público.

\section{Conclusão}

Os estudos realizados comprovam que a definição da função social da universidade e do perfil do intelectual aqui apresentados são convergentes e coerentes com possibilidades e necessidades de oferecer ao movimento negro o fortalecimento de suas reivindicaçôes de políticas públicas, paralelamente à revisão de equívocos vigentes em tais políticas e a sua efetiva realização no espaço da prática.

Por outro lado, teorias sobre o papel dos movimentos sociais ainda são, em grande parte, centradas nos movimentos de luta das classes trabalhadoras, em uma hierarquia que pretende colocar os demais movimentos subsumidos à questão do trabalho, em uma situação periférica, ainda que a realidade concreta evidencie a autonomia raça/classe.

As relaçóes estabelecidas entre a academia e tais movimentos estão a exigir estudos particulares, com ênfase no caráter complementar das metodologias quantitativa/qualitativa, a fim de que se compreenda a natureza de tais relaçóes, que têm contribuições significativas de Munanga (1997, 2019) e Santos(1998). Essas investigaçóes precisam ser ampliadas neste momento histórico em que novas 
situações permeiam o ambiente universitário, desafiando os dois movimentos a estabelecerem relaçóes desprovidas de disputas, com o propósito de construir uma universidade na qual a presença negra, em todos os seus quadros, se faça presente em percentuais equiparáveis a sua presença na população e de fazer desaparecer o racismo epistêmico que caracterizam os currículos dos cursos universitários.

\section{Referências}

ALBERT, V.; PEREIRA, A. A. (Orgs.). Histórias do movimento negro no Brasil.Rio de Janeiro: Pallas; CPDOC-FGV, 2007.

ANTUNES, R. Os sentidos do trabalho: ensaios sobre a afirmação e a negação do trabalho. São Paulo: Boitempo, 2001.

BICUDO, V. L. Atitudes raciais de pretos e mulatos em Sáo Paulo. Edição organizada por Marcos Chor Maio. São Paulo: Sociologia e Política, 2010.

CAPES - Coordenação de Aperfeiçoamento de Pessoal de Nível Superior. Disponível em: www.capes.gov.br.

CUNHA, L. A. Que universidade? São Paulo: Cortez, 1989.

FERNANDES, F. A integraçáo do negro na sociedade de classes. São Paulo: Ática, 1978. (v. 1-2).

GOHN, M. da G. Movimentos sociais e educaçáo. São Paulo: Cortez, 1992.

.Teorias dos movimentos sociais: paradigmas clássicos e contemporâneos. São Paulo: Loyola, 2008.

. Novas teorias dos movimentos sociais. São Paulo: Loyola, 2008.

IANNI, O. A racialização do mundo. Tempo Social, São Paulo: USP,v. 8, n. 1, p. 1-23, maio 1996.

INEP - Instituto Nacional de Estudos e Pesquisas Educacionais Anísio Teixeira. Disponível em: www.inep.gov.br.

MOORE, C. Racismo \& sociedade: novas bases epistemológicas para entender o racismo. Belo Horizonte: Mazza, 2007.

MUNANGA, K. Relaçóes entre a academia e a militância negra. In: Congresso Afro-brasileiro, 5. Anais... Salvador, 1997, p. 9.

. Tensão e distensão entre pesquisadores brancos e universitários negros. Conferência de abertura do X Congresso Brasileiro de Pesquisadores Negros. Uberlândia, MG, 2018. 
GONZAGA, J. D. O protagonismo do negro no estudo das raças no Brasil. Resistência Revista: Revista do X COPENE - Congresso Brasileiro de Pesquisadores Negros,Uberlândia, Associação Brasileira de Pesquisadores/as Negros/as; Universidade Federal de Uberlândia (UFU), p. 22-27,2018.

NOVAES, A. (Org.). O silêncio dos intelectuais. São Paulo: Companhia das Letras, 2006.

OLIVEIRA, I. de(Org.). Negritude e Universidade: evidenciando questóes relacionadas ao ingresso e aos projetos curriculares. Rio de Janeiro/Niterói: FAPERJ/Alternativa, 2015.

OLIVEN, A. C. A marca da origem: comparando colleges norte-americanos e faculdades brasileiras. Cadernos de Pesquisa,São Paulo,v. 35, n. 125,p. 111-135, maio/ago. 2005.

SANTOS, M. O intelectual e a universidade independente. Revista USP, São Paulo, n. 39, p.54-57, 1998.

. O intelectual e o dever da crítica. São Paulo: Humanitas Publicaçôes; FFLCH USP, 1998. (Série Eméritos 1).

. Da discriminação à consciência coletiva. Cadernos Cidadáo, São Paulo, n. 9, p. 4, 1998.

. Por uma outra globalizaçáo: do pensamento único à consciência universal. São Paulo: Record, 2000.

SILVA, C. B. R. da. Trajetórias do movimento negro e ação afirmativa no Brasil. In. MÜlLER, Tânia Mara Pedroso; OLIVEIRA, Iolanda (Orgs.). Cadernos Penesb,n. 10. Rio de Janeiro/Niterói: EdUFF, 2008/2010, p.117-138.

SOUZA, N. S. Tornar-se negro. Rio de Janeiro: Graal, 1983.

VEIGA-NETO, A. É preciso ir aos porôes. Revista Brasileira de Educaçáo [online], Rio de Janeiro, v. 17, n. 50, p.267-282, maio/ago. 2012. Disponível em: https://www.scielo.br/pdf/rbedu/v17n50/v17n50a02.pdf 